\title{
Survey of neonatal resuscitation practices in metropolitan and non-metropolitan non-tertiary birthing units in New South Wales and Australian Capital Territory.
}

Dharmesh Shah ( $\sim$ dharmesh.shah@health.nsw.gov.au )

Westmead Hospital WNH: Westmead Hospital Women's \& Newborn Health Department https://orcid.org/0000-0002-2074-2859

Kalpesh Jain

Sydney West Area Health Service - SWAHS: Western Sydney Local Health District

Mark Tracy

Westmead Hospital Women's \& Newborn Health Department

Nadia Badawi

Children's Hospital at Westmead

\section{Short Report}

Keywords: Newborn, resuscitation, survey, birthing unit

Posted Date: March 3rd, 2022

DOI: https://doi.org/10.21203/rs.3.rs-1371068/v1

License: (c) (1) This work is licensed under a Creative Commons Attribution 4.0 International License.

Read Full License 


\section{Abstract}

\section{Purpose}

Newborn infant is particularly vulnerable around the time of birth and events during this period can have impact on survival and neurodevelopmental outcomes. Having trained personnel with familiar equipment is of paramount importance. We aimed to explore the neonatal training experience of birth attendants in New South Wales (NSW) and Australian Capital Territory (ACT) and explore the variations in respiratory management and equipment use at birth.

\section{Methods}

We contacted 119 non-tertiary units in NSW/ACT by a written survey followed by telephone contact. A set questionnaire was offered, asking for details of the availability and skill levels of staff at neonatal resuscitation, and of the equipment available at all births.

\section{Results}

Staff from 103 out of 119 units (87\%) participated in the study. Resuscitation at all metropolitan units was supported by qualified Paediatricians whereas midwives provided neonatal resuscitation as the first responder in a non-metropolitan unit, with support from a general medical practitioner. Twenty two percent of non-tertiary units relied on external agencies or online support for neonatal resuscitation training. Three quarters of the units used a T-piece resuscitator as the primary device to provide positive pressure ventilation, $65.3 \%$ of non-metropolitan units had blenders available, and $19 \%$ of units administered some oxygen at initiation of resuscitation. Thirty eight percent units responded having no prior knowledge of the pressure relief valve setting.

\section{Conclusion}

Equipment and availability of trained personnel for neonatal resuscitation in non-tertiary birthing units across NSW and ACT wary widely. The resources to provide training and education are variable.

\section{What Is Known}

Neonatal resuscitation is widely performed around Australian non-tertiary birthing units.

There is a wide variation in practices around resuscitation skills and use of equipment across birthing units world wide.

\section{What Is New}

There is variation in the availability, training and use of neonatal resuscitation equipment in non-tertiary birthing units around Australia. 
Non-tertiary birthing unit especially non-metropolitan units continue to have limited ability to blend air and oxygen.

Access to training and education for neonatal resuscitation is variable across the units.

\section{Introduction}

Newborn resuscitation is widely performed globally and of the estimated 140 million newborn infants born annually around the world, almost $5 \%$ receive positive pressure ventilation (PPV) [1]. The NSW Health recommendation, supported by the Australian Resuscitation Council (ARC), mandates personnel trained in advanced neonatal resuscitation must be on call for low risk and in attendance of high-risk births [2]. Failure to provide adequate support and resuscitation at birth could lead to long term morbidity and increased mortality. Improved resuscitation training and skills which are regularly updated could result in reduction of early neonatal mortality [3]. There is a wide variation in practices around resuscitation skills and use of equipment. Foster et al surveyed health personnel across the birthing units in NSW and ACT in 2006, and reported a lack of effective neonatal resuscitation training among birth attendants especially in non-tertiary units [4]. The availability or use of resuscitation devices, equipment and use of oxygen at birth varies around the world and across Australia and New Zealand $[5,6]$.

Our study aimed to:

1. Investigate the availability of adequate equipment for neonatal resuscitation at birth in non-tertiary birthing units in NSW and ACT

2. Examine the differences in practice between metropolitan and non-metropolitan units

3. Evaluate training resources available for neonatal resuscitation

\section{Methods}

We surveyed neonatal resuscitation practices in various non-tertiary birthing units in NSW and ACT in 2017, specifically, personnel, the availability, types and utilisation of equipment and staff education. Hospitals in Australia are classified by the Australian Institute of Health and Welfare into "Peer groups" from $A$ to $D$, group A being tertiary down to group D remote units [7]. NSW/ACT is divided into seven rural and regional and eight metropolitan regions. The non-tertiary birthing units (public and private hospitals) were identified from the NSW Local Health Districts and Specialty Network [8]. One hundred and nineteen units were identified. The nurse unit managers and/or nurse educators of the birthing suite / special care unit were contacted by a web-based survey (SurveyMonkey ${ }^{\circledR}$ ) questionnaire. In the absence of a response after four weeks, a reminder was sent, followed by further phone contact if necessary. Ethical approval was granted by the local ethics committee as a quality assurance project. (Western Sydney Local Health District, Human Research Ethics Committee, 4256 QA). Data were collected in an Excel spread sheet and analysed using Stata Statistical software version 14 (Stata Corp., College Station, TX, USA). Pearson's chi-squared test was used to compare data. 


\section{Results}

One hundred and three of the 119 (86.5\%) units surveyed responded, of which 28 (27.2\%) were metropolitan and 75 (72.8\%) were non-metropolitan (Table 1). The non-metropolitan birthing units were smaller in size, with almost $75 \%$ units birthing fewer than 500 babies annually, compared to metropolitan units where more than $89 \%$ units birthed over 1000 babies annually. 
Comparison of metropolitan versus non-metropolitan units

\begin{tabular}{|c|c|c|c|}
\hline$n=103$ & $\begin{array}{l}\text { Metropolitan } \\
(\mathrm{n}=\mathbf{2 8})\end{array}$ & $\begin{array}{l}\text { Non- } \\
\text { metropolitan } \\
(n=75)\end{array}$ & $\begin{array}{l}p \\
\text { value }\end{array}$ \\
\hline Number of births per year & $0(0 \%)$ & $28(37.3 \%)$ & \multirow[t]{5}{*}{0.000} \\
\hline$<100$ & $3(10.7 \%)$ & $29(38.7 \%)$ & \\
\hline $100-500$ & $6(21.4 \%)$ & $6(8 \%)$ & \\
\hline $501-1000$ & \multirow[t]{2}{*}{$19(67.9 \%)$} & \multirow[t]{2}{*}{$12(16 \%)$} & \\
\hline$>1000$ & & & \\
\hline \multirow{2}{*}{$\begin{array}{l}\text { Most specialised level of medical support at } \\
\text { resuscitation }\end{array}$} & $27(96.4 \%)$ & $27(36 \%)$ & \multirow{3}{*}{$\begin{array}{l}< \\
0.001\end{array}$} \\
\hline & \multirow[t]{2}{*}{$1(3.6 \%)$} & \multirow[t]{2}{*}{$48(64 \%)$} & \\
\hline Medical officer/general practitioner & & & \\
\hline Who provides training? & $8(28.6 \%)$ & $6(8 \%)$ & 0.004 \\
\hline Paediatrician & $17(60.7 \%)$ & $49(65.3 \%)$ & \\
\hline Nurse educators & $3(10.7 \%)$ & $20(26.7 \%)$ & \\
\hline \multicolumn{4}{|l|}{ Online/external agencies } \\
\hline Blenders to deliver oxygen at resuscitation & $27(96.4 \%)$ & $49(65.3 \%)$ & $\begin{array}{l}< \\
0.001\end{array}$ \\
\hline Air vs oxygen at resuscitation & $24(85.7 \%)$ & $63(84 \%)$ & 0.348 \\
\hline Air & $4(14.3 \%)$ & $12(16 \%)$ & \\
\hline \multicolumn{4}{|l|}{ Oxygen } \\
\hline First choice of equipment & $26(92.9 \%)$ & $52(69.3 \%)$ & 0.013 \\
\hline T-piece device & $2(7.1 \%)$ & $23(30.7 \%)$ & \\
\hline \multicolumn{4}{|l|}{ Self-Inflating Bag } \\
\hline Self-inflating bag & $22(78.5 \%)$ & $66(84.6 \%)$ & 0.07 \\
\hline Disposable & $6(21.4 \%)$ & $12(15.4 \%)$ & \\
\hline Re-usable & & & \\
\hline
\end{tabular}




\begin{tabular}{|c|c|c|c|}
\hline$n=103$ & $\begin{array}{l}\text { Metropolitan } \\
(n=28)\end{array}$ & $\begin{array}{l}\text { Non- } \\
\text { metropolitan } \\
(n=75)\end{array}$ & $\begin{array}{l}p- \\
\text { value }\end{array}$ \\
\hline Initial peak inspiratory pressure at resuscitation & $17(60.7 \%)$ & $38(50.7 \%)$ & 0.01 \\
\hline $25 \mathrm{~cm} \mathrm{H}_{2} \mathrm{O}$ & $11(39.3 \%)$ & $17(22.7 \%)$ & \\
\hline $30 \mathrm{~cm} \mathrm{H}_{2} \mathrm{O}$ & 0 & $20(26.6 \%)$ & \\
\hline \multicolumn{4}{|l|}{ Other/not known } \\
\hline Pressure relief valve setting $\left(\mathrm{cm} \mathrm{H}_{2} \mathrm{O}\right)$ & $18(62.3 \%)$ & $42(56 \%)$ & 0.50 \\
\hline$\leq 40$ & $2(7.2 \%)$ & $3(4 \%)$ & \\
\hline$>40$ & $8(28.5 \%)$ & $30(40 \%)$ & \\
\hline \multicolumn{4}{|l|}{ Not known } \\
\hline Biomedical equipment checks & $17(60.7 \%)$ & $55(73.3 \%)$ & 0.214 \\
\hline Annual & $6(21.4 \%)$ & $13(17.3 \%)$ & \\
\hline 6 monthly & $5(17.8 \%)$ & $7(9.3 \%)$ & \\
\hline Not known & & & \\
\hline
\end{tabular}

\section{Use of oxygen at neonatal resuscitation}

Ninety-seven percent of the metropolitan birthing units had the capacity to blend air and oxygen, and all, but four units used air at the initiation of resuscitation. In contrast, only $65.3 \%$ of the non-metropolitan units had blenders available. Sixteen percent of those units were still using some oxygen ( $21 \%$ to $100 \%)$ for initiation of resuscitation at birth for term infants.

\section{Equipment at resuscitation}

The T-piece resuscitator (TPR) was commonly used to provide PPV across the birthing units, although almost a third of non-metropolitan units used a self-inflating bag (SIB) as the first choice for resuscitation at birth. Almost three-quarters of the units in NSW/ACT used a SIB. The setting of the TPR was variable across the units. The peak inspiratory pressure (PIP) and the pressure relief valve settings varied widely. Almost a third of the units were not aware of the pressure relief valve settings (Fig. 1). None of the units surveyed had electrocardiograph (ECG) monitoring available or were aware of the current guideline recommending possible use of ECG at birth. All units reported, the availability of a pulse oximeter.

\section{Training and education}

All the metropolitan units had a paediatrician available on call for neonatal resuscitation at birth, whereas only $36 \%$ of non-metropolitan birthing units had an on-call paediatrician. All units reported midwives as 
the primary personnel at neonatal resuscitation. More than a third of the non-metropolitan birthing units had fewer than 100 births annually and another third had 100 to 500 births annually. Almost two-thirds of the non-tertiary birthing units had support for in-house training, but almost a quarter of nonmetropolitan units relied on external agencies or online support for their neonatal resuscitation training. All except three non-metropolitan units reported annual training of their midwives in neonatal resuscitation.

\section{Ongoing equipment checks and national guidelines}

The pressure relief valve setting on the TPR was variable, and 38 out of the 103 units reported being unaware of the safety feature. All units recommended use of a national guideline with a simplified algorithm in neonatal resuscitation for non-tertiary settings. Almost all units $(92 \%)$ had a resuscitation protocol attached to the resuscitaire.

\section{Discussion}

This is the first survey including non-tertiary birthing unit settings looking at the resources, equipment, and education of staff for newborn resuscitation. Non-metropolitan units have a lower number of births per year and maintaining their skills and quality control of the equipment is difficult but important. Our study shows that more than a third of non-metropolitan units had fewer than 100 births per year and another third had fewer than 500 a year (equivalent to fewer than two a day). The availability of skilled personnel at the birth of a newborn infant is essential. In a non-metropolitan NSW birthing hospital, midwives with the support of a general practitioner were the primary resuscitators for the newborn. Foster et al reported that there was an urgent need to train health professionals in neonatal resuscitation [4]. They reported that a third of respondents in rural and urban non-tertiary units were not up-to-date with resuscitation skills and almost a quarter of staff were not confident about their newborn resuscitation skills. Lack of availability of resources for training was identified from the survey question "Who trains your staff for neonatal resuscitation?" This was more evident in non-metropolitan birthing units, where they were more reliant on external agencies and online courses. Maintaining knowledge and skills in neonatal resuscitation is essential for midwives. Caldelari et al evaluated the neonatal resuscitation skills of student midwives and reported that they maintained global levels of theoretical knowledge, but practical skills were often not retained [9]. Pleasingly, our survey showed that almost $98 \%$ of the birthing units provided annual training for their midwives, although there was no consistency in training modality.

Resuscitation with air is the current recommendation for term infants according to the current ARC guidelines [10]. The availability of blenders has improved, although almost a third of non-metropolitan units have none. Bhola et al reported only one in five non-tertiary units had the ability to blend oxygen highlighting the need for air and oxygen sources, blenders and pulse oximeters at all birthing units [11]. We looked at the availability of ECG monitoring in the birthing unit for neonatal resuscitation. The 2016 ARC guideline suggested using ECG monitoring for rapid and accurate display of heart rate, although the evidence for this is weak. None of the units were aware of this guideline. 
The ARC guideline recommends using a TPR to provide Positive End Expiratory Pressure (PEEP) for term resuscitation. Most metropolitan and almost two-thirds of non-metropolitan units use a TPR as primary mode of ventilation. A TPR needs a continuous flow of gases and requires adequate supervision and training of staff. Our study highlights the variation in the PIP (initial PIP) and the safety valve settings. Almost a third of non-metropolitan birthing units were not aware of the safety (pressure relief valve) settings. The factory settings of the pressure relief valve on SIB vary from 35 to $45 \mathrm{~cm} \mathrm{H}_{2} \mathrm{O}$. In addition, the pressure relief valve setting in TPR is flow dependent. Hawkes et al reported inadvertent increase in PIP and PEEP with increase in flows, hence the maximum pressure relief valve is not a true pop off valve [12]. It is important that staff check the pressure relief valve with a standard flow in their unit.

\section{Conclusion}

There is significant variation in the use and availability of equipment for neonatal resuscitation especially at non-metropolitan birthing unit. Training of personnel and availability of skilled staff for resuscitation of the newborn at birth is inconsistent across birthing units, especially out of metropolitan regions. The availability of equipment, especially oxygen blenders, and regular checking of equipment is essential.

\section{Abbreviations}

ACT Australian Capital Territory

ARC Australian Resuscitation Council

ECG Electro cardio gram

NSW New South Wales

PEEP Positive End Expiratory Pressure

PIP Peak Inspiratory Pressure

PPV Positive Pressure Ventilation

SIB Self Inflating Bag

TPR T-piece Resuscitator

\section{Declarations}

\section{Funding}

The authors declare that no funds, grants, or other support were received during the preparation of this manuscript. 


\section{Competing Interests}

The authors have no relevant financial or non-financial interests to disclose.

\section{Availability of data and material}

Not applicable

\section{Code availability}

Not applicable

\section{Author Contributions}

DS and MT conceptualised, analysed, written, and edited the manuscript, $\mathrm{KJ}$ conducted the web based and telephonic survey, NB edited and critically appraised the manuscript.

\section{Consent to participate}

Not applicable

\section{Consent to publish}

Not applicable

\section{References}

1. Wyckoff MH, Wyllie J, Aziz K, de Almeida MF, Fabres J, Fawkes J, Guinsburg R et al. (2020) Neonatal Life Support: 2020 International Consensus on Cardiopulmonary Resuscitation and Emergency Cardiovascular Care Science with Treatment Recommendations. Circulation 142:S185-S221.

2. NSW Government GL2018_016. Maternity - Resuscitation of newborn infant.

3. Dempsey E, Pammi M, Ryan AC, Barrington KJ (2015) Standardised formal resuscitation training programmes for reducing mortality and morbidity in newborn infants. Cochrane Database Syst. Rev. (9).

4. Foster K, Craven P, Reid S (2006) Neonatal resuscitation educational experience of staff in New South Wales and Australian Capital Territory hospitals. J Paediatr Child Health 42:16-19.

5. Mann C, Ward C, Grubb M, Hayes-Gill B, Crowe J, Marlow N (2012) Marked variation in newborn resuscitation practice: A national survey in the UK. Resuscitation 83:607-611.

6. O’Donnell, Davis PG, Morley CJ (2004) Neonatal resuscitation: Review of ventilation equipment and survey of practice in Australia and New Zealand. J Paediatr Child Health 40:208-212.

7. AlHW: Monk A, Harris K, Donnolley N, Hilder L, Humphrey M, Gordon A \& Chambers GM 2016. Perinatal deaths in Australia, 1993-2012. Perinatal deaths series no. 1. Cat. no. PER 86. Canberra: AlHW 
8. NSW Health PD2006_NSW Health Guide to the Role Delineation of Clinical Services, First Edition, January 2016. Section 2 D4 Neonatal.

9. Calderali M, Floris L, Marchand C, Schuler Barazzoni M (2019) Maintaining the knowledge and neonatal resuscitation skills of student midwives 6 months after an educational program. Arch de Pediatr 26:385-392.

10. Australian Resuscitation Council. Australian Resuscitation Council Guidelines. Section 13: Neonatal Guidelines. 2021. Available at http://www.resus.org.au. (Accessed February 2022).

11. Bhola K, Lui K, Oei JL (2012) Use of oxygen for delivery room neonatal resuscitation in non-tertiary Australian and New Zealand hospitals: A survey of current practices, opinion and equipment. J Paediatr Child Health 48:828-832.

12. Hawkes CP, Oni OA, Dempsey EM, Ryan CA (2009) Potential hazard of the Neopuff T-piece resuscitator in the absence of flow limitation. Arch of Dis Child Fetal Neonatal Ed. 94:F461-F463.

\section{Figures}

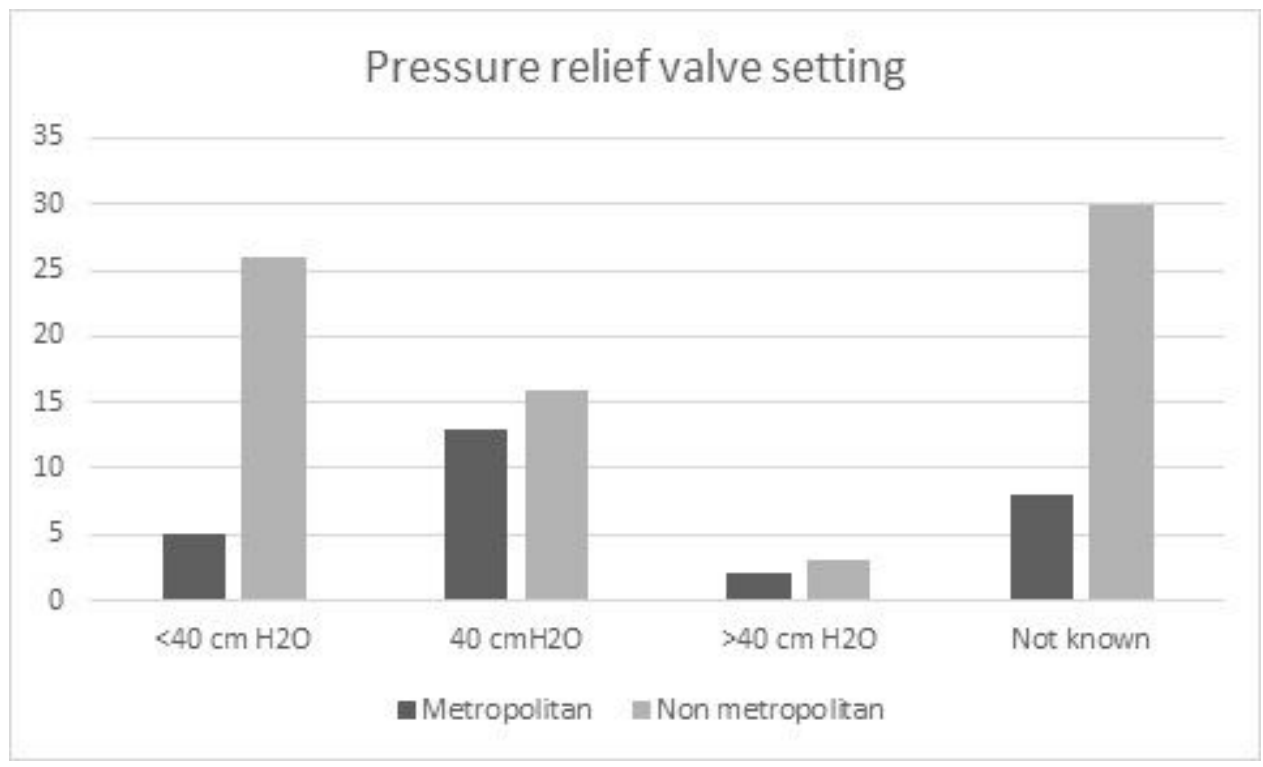

\section{Figure 1}

Differences in the pressure relief valve setting on the T-piece devices among the metropolitan and nonmetropolitan units

\section{Supplementary Files}

This is a list of supplementary files associated with this preprint. Click to download.

- Electronicsupplementarymaterial.docx 